\title{
Developing Lexical Richness among EFL Students: Effect of Morphological Awareness Training on Writing Performance
}

\author{
Dr. Hanan Gamal Mohamed Ebedy \\ Lecturer of Curriculum and Instruction (TEFL) \\ Misr University for Science and Technology
}

\section{Abstract}

This study aimed to investigate the effectiveness of
morphological awareness training program in
developing lexical richness among first-year English majors at the Faculty of Foreign Languages and Translation, Misr University for Science and Technology in terms of lexical density and variation. Quasi-experimental method was adopted with its pretestposttest control group design. A training program on morphological awareness was developed to fulfill the purpose of the study. Sixty students participated in the study; ( 30 ) in the experimental group and (30) in the control group. The results pinpointed the effectiveness of morphological awareness training program in developing lexical richness among EFL majors in favor of the posttest of lexical density and variation among the experimental group students. The study recommended training teachers on morphological awareness to help their students develop their lexical richness.

Keywords: Morphological Awareness, Writing Performance, Lexical Richness, Lexical Density, Lexical Variation,

\section{Introduction}

Good writing is characterized by a number of features. In addition to coherence, meaningful connections between ideas, proper use of punctuation, and grammatical accuracy, a few scholars also suggest lexical richness, which is defined as a variety of lexis (Malvern \& Richards, 2012). Laufer \& Nation (1995, p. 307) maintain that "a well-used vocabulary is likely to have a positive effect on the reader". In many composition scoring guideline it has also been one of the criteria of good writing . The one proposed by Jacobs et al (1981) included vocabulary variation as one of the writing sub-skills to be judged. Siskova (2012) proposes different measures of lexical richness, namely lexical sophistication (how many advanced words are 
used), lexical diversity (how many different words are used), and lexical density (what is the proportion of content words in the text). Read (2000) argues that knowledge of diverse words enable learners to avoid repetition of words by synonyms, superordinates, and other related words. Thus, it makes sense to expect advanced EFL learners to demonstrate high lexical richness in their written works.

Recent years, there have been suggestions about using morphological cues to infer the word's meaning in FL acquisition (Morin, 2003; Chang, Wagner, Muse \& Chow, 2005; and Schiff \& Calif, 2007). As Venezky (1999) proposed English language is called as a morphophonemic language because of special relationship between phonology and morphology. Besides phonology, there is also strong relationship among morphology, sentence building, reading, comprehension and writing. As long as individuals who are learning English as a foreign language realize morphemes in complex words, they may learn and acquire vocabulary items easily.

Morphological awareness is a skill that allows language learner to understand the structure of words. Researchers claimed that when students understand the morphological nature of words, they show impressive results in the development of various literacy skills such as reading, speaking, listening and writing (Oz, 2014). As English language contains number of words, the better way to learn new words and to increase the vocabulary is to understand common prefixes and suffixes. By knowing suffixes and prefixes, their rules and meanings, students get aware of the morphological structures of the new words of English language. Morphological awareness refers, according to Carlisle(1995), to individual's explicit knowledge. It also raises awareness of the internal structure of words and their capacity to reflect upon and manipulate upon their structure. Kuo and Anderson (2006), emphasized that understanding of word formation is necessary while Liu and McBride-Chang (2010), noted that morphological awareness is frequently associated with the development of reading and writing skills. Oz (2014), mentioned that learners who understand affixation with word formation process perform better and become proficient in language. Thus, the current 
study emanates from the assumption that training students on morphological awareness may enhance their lexical richness in terms of lexical density and lexical variation.

\section{Background}

In the context of English as a Foreign Language, writing is a skill that is of paramount importance for students. When writing their research reports or internship reports, they need to make great efforts to make the reports not only contributive to the field but also coherent. In addition to that, they are expected to demonstrate the use of varied words so as to create a mature English academic style. Lemmouh (2008) highlights the facts that the ability to use advanced words and various lexical items correlate strongly with school achievements. Diverse words also promote variation in a written work, a quality that avoids monotonous and tedious tone throughout the essay. Although the foreign language acquisition process is understood better by comprehending the human brain processes and how it learns new information, mainly focusing on the learner as an individual. As the lexicon is a part of it and it is chosen based on the assumption that learning component of foreign language concentrates on transition theories to property theories of the framework. The main focus here is as an individual learner (Mitchell \& Myles, 2004, p. 95). The lexicon may indeed be the most prominent language component for learners in the development of the language.

Learning a foreign language is often related to knowing the words and the sentences. The knowledge of words is called lexical richness. Kyle \& Crossley (2016) stated that lexical richness is the measurement of how rich the students' have in writing and composing the words or lexical in a good essay. In relation to the occurrences of lexical richness, Djiwandono (2016) asserted that these occurrences were majorly triggered by the foreign language use that can be further acknowledged from its sophistication and FL learner's productive vocabulary. Lexical development is explored using measures such as lexical density (proportion of content words), lexical variation (vocabulary range) (Viadkovic \& Barker, 2009). The two measures that are often used to describe lexical development particularly are lexical variety and lexical density. Lexical density 
is a measure to find out how many lexical items such as nouns, verbs, adjectives, and adverbs used in the text, while lexical variety provides a measure of how many different words are used in a text. Both the lexical variety and lexical density have been shown significantly higher in writing than in speaking (Halliday, 1989).

It should be noted that in the analysis of lexical richness, the text needs to be transcribed and formatted in advance for easy processing of data (Daller, 2010). Gharibi \& Boers (2017) said that by using lexical richness, researchers can identify the weaknesses and advantages of the object of the research. It can also make it easier to calculate the lexical property that is controlled by a person. The use of lexicon as a research object is based on the asumsion that every person would need good words to write a whole good sentence. Word selection required vocabulary richness so that later there is no repetition of words in each sentence because it will affect the calculation of lexical richness (Caselli, Caselli, \& Goldberg, 2016; Gharibi \& Boers, 2017; and Suggate \& Stoeger, 2017). Lexical richness provides some options of techniques to researchers who want to collect the data in many ways, such as lexical originality, lexical density, lexical diversity and lexical sophistication. Those terms are also having each tool to determine the lexical richness on each student's writing knowledge.

Laufer and Nation (1995: 309) list several measures for measuring lexical richness: lexical density (LD), lexical originality (LO), lexical sophistication (LS) and lexical variation (LV). The lexical originality index "measures the learners' performance relative to the group in which the composition was written." Laufer and Nation (1995) argue that such a measure is not reliable because it is defined not only by the composition in question but also by the group factor (LO is calculated by multiplying the number of tokens unique to one writerx100 and dividing it by the total number of tokens); b) LD is defined as the percentage of lexical words in the text, i.e., nouns, verbs, adjectives, adverbs; c) LS is the percentage of 'advanced' words in the text (№ of advanced words x100/ total number of lexical tokens), while d) $\mathrm{LV}$ is the type/token ratio, i.e., the ratio measured as a percentage between the total number of running 
words and the different words in the text (number of words $\mathrm{x}$ $100 /$ number of tokens). LV has proved to be unstable for short texts and may be influenced by differences in length. This study focuses on $\mathrm{LD}$ and $\mathrm{LV}$.

Researchers believed that due to the morphological differences between English and other languages, students feel difficulty to comprehend meanings of the words (Birch, 2007). On the other side, few believed that instruction methods are not sufficient enough to make students aware about the smallest meaningful units of language (Kieffer \& Box, 2013). Oz in (2014), clarified morphological awareness while mentioning different researches that there is a clear difference between students who understand and do not understand morphemic structures. He added that students must have strong grip on reading comprehension perform better in writing. Whereas, Carlisle (2010) discussed the importance and effects of instruction in Morphological awareness and found that students' literacy development and educational value can be increased if they are given proper instruction. He further highlighted the need to provide clear understanding of morphological awareness instruction and teaching strategies.

The ability to use the knowledge of word formation rules and the pairing between sounds and meanings is called morphological awareness (Kuo \& Anderson, 2006). Chang et al. (2005, p. 417) defines morphological awareness as "the awareness of and access to the structure and meaning of morphemes in relation to word". Morphological awareness provides learners with two types of abilities: synthetic aspect (morphological structure awareness), the ability to make use of linguistic knowledge to drive new meanings and reassemble smaller meanings to make up new words, on the one hand and analytic aspect (morpheme identification awareness), the ability to distinguish different meanings across homophones and break down complex words into smaller meanings on the other (Chang et al., 2005). Carlisle (1995, p. 94) defines morphological awareness as “.... Children's conscious awareness of morphemic structure of words and their ability to reflect on and manipulate that structure". With morphological awareness, learners are able to learn morphemic boundaries and morphemes by 
disassembling complex words into meaningful parts (e.g. adulthoods= adult + -hood +- s), affixes (adult $=$ not child, - hood= the state of being, $-s=$ to indicate plural nouns), learning the meanings of roots, and reassembling the meaningful parts into new meanings (brotherhood, fatherhood, motherhood, and childhood).

Morphological awareness, which is a vocabulary acquisition strategy, is the process of breaking down morphologically complex words into their constituent morphemes. McBrideChang et. al. (2005) defined morphological awareness as, "Awareness of and access to the meaning and structure of morphemes in relation to words". It was found that teaching morphologically complex vocabulary along with providing a working knowledge of morphemes are beneficial for college students (Bellomo, 2009), and Apel \& Diehm (2014) showed that teaching how affixes are added to a root or base to form a more complex derivation can be understood even by first graders. So teachers can train students to add derivational suffixes to already existed word to form new different grammatical word class.

Morphology plays a role in word choice and sentence construction in writing. In order for writers to find the correct and precise words they want to use, they must understand what words mean. Part of a word's meaning is contained in its semantic properties, or a description of the item's quality, kind, number, etc. However, the meaning of a word is also contained in its morphological structure, or its form (Carlisle, 2000; Carlisle \& Fleming, 2003; and Perfetti, 2007). The morphological structure of a word can tell a writer the word's grammatical category, acceptable forms, and proper usage (e.g., the suffix -ly can only be attached to verbs, not nouns). Being able to recognize morphological relationships between words gives students access to different word forms and vocabulary choices when writing text (Green, McCutchen, Schwiebert, Quinlan, Eva-Wood, \& Juelis, 2003; Bowers, Kirby, \& Deacon, 2010; and Nagy, Carlisle, \& Goodwin, 2014).

Maag (2007) identifies words in two categories such as multimorphemic and monomorphemic words. Monomorphemic words, (e.g, elephant, window) are additionally called as root words. Multimorphemic words, (e.g, worthiness, suspicious), are 
made out of linked morphemes. Inflectional changes reflect linguistic elements of words, with changes of tense, number, and person. Word's class or part of speech do not change according to inflections; for example, talk /talks /talked /talking, chair /chairs. Changes in derivational morphology permit a root word or stem to involve different word classes, as in obviousness (noun), obvious (adjective), obviously (adverb). It incorporates information of derivational morphology, for example, additions (e.g., the -er in seller to show a person who sells), prefixes (e.g., the dis-in disorganized to demonstrate the antonym of the first, organized), and compounding (e.g., airplane to produce one word combining two words; air and plane). Then again, learning of inflectional morphology concentrates essentially on showing linguistic changes in words such as play and played. It was supposed that if a student knows one word form, he/she can understand the other part of speech meanings (Nurhemida, 2007).

In research area, morphological awareness studies on the basis of adults and the effects of morphological awareness on vocabulary size, word-based text writing and comprehension ability have represented distinctive aspects on foreign language learning research area (McCutchen, Green, \& Abbott, 2008; Apel, Diehm, \& Apel, 2013; Herman, Gilbert Cote, Reilly,\& Binder, 2013; Tighe \& Binder, 2013, 2014; and Fracasso, Bangs, \& Binder, 2014). Thus, for FL learners, knowledge of English morphology makes a significant contribution to the vocabulary size, reading abilities, writing success and other language skills. In consequence, the present study attempts to explain the significant impact of morphological awareness on the lexical richness in writing performance of English language students. It is expected that this study will help English language learners as well as language teachers to adequately structure their lesson plans for English courses to meet this language learning need of students.

\section{Statement of the problem}

First year EFL majors at the Faculty of Foreign Languages and Translation, Misr University for Science and Technology lack the adequate training required for developing a dynamic living lexicon. Hence, the researcher finds that the morphological 
awareness training will be a good contributor to develop lexical richness. Therefore, the following questions are raised:

1- What is the effectiveness of a morphological awareness training program in developing lexical density of first-year EFL majors, at Faculty of Foreign Languages and Translation?

2- What is the effectiveness of a morphological awareness training program in developing lexical variation of first-year EFL majors, at Faculty of Foreign Languages and Translation?

\section{Purpose of the Study}

The purpose of the present study is to:

1- develop lexical density and lexical variation among first-year EFL majors, at Faculty of Foreign Languages and Translation, Misr University for Science and Technology.

2- provide a morphological awareness training program for firstyear EFL majors, at Faculty of Foreign Languages and Translation, Misr University for Science and Technology with the aim at developing their lexical density and lexical variation.

3- investigate the effectiveness of the proposed morphological awareness training program in developing first-year EFL majors' lexical density and lexical variation.

\section{Hypotheses of the Study}

The following four hypotheses were formulated:

1 - There is a statistically significant difference between the mean scores of the experimental group learners and those of the control group in their lexical density as measured by the writing test after the treatment.

2- There is a statistically significant difference between the mean scores of the experimental group learners in their lexical density as measured by the writing test before and after the treatment.

3- There is a statistically significant difference between the mean scores of the experimental group learners and those of the control group in their lexical variation as measured by the writing test after the treatment. 
4- There is a statistically significant difference between the mean scores of the experimental group learners in their lexical variation as measured by the writing test before and after the treatment.

\section{Definition of terms}

\section{Lexical Richness}

Lexical richness is defined as the ratio of types of words to the total words written in a text (Hoover, 2003). Lu (2012) has conceptualized lexical richness as "a multidimensional feature of a learner's language use that consists of the following four interrelated components: lexical density, lexical sophistication, lexical variation, and number of errors in vocabulary use" (p. 189). In 2014, Zhang defined lexical richness of a speaker, in a quantitative sense, as "the amount of vocabulary that the speaker freely uses in discourse". From Zhang's point of view, lexical richness reflects the speaker's ability and skills in maneuvering the basic units of speech, the richer lexicons used in the discourse, the higher degree of variations and density perceived (p. 61). Operationally, the term 'lexical richness' refers to the amount of words the EFL learners written produce. It is measured in terms of two dimensions; lexical density and lexical variation.

\section{Lexical Density}

Lexical density is characteristic of written English, and is typically achieved through use of fewer clauses and greater embedding, particularly in the noun phrase (Halliday, 1989). lexical density can be seen as reflecting an individual's ability to use words resourcefully in text construction (Biber, 1999). Lu (2012) used lexical density as the ratio of the number of lexical (as opposed to grammatical) words to the total number of words in a text. Spoken texts reportedly have a lower lexical density than written, and lexical density in learners' oral productions may be affected by such factors as plannedness and degree of interactiveness (p. 191). Lexical density is calculated as a ratio of the number of content words which are the primary carriers of meaning (nouns, adjectives, verbs, etc.) to the total number of words in a text and is expressed as a percentage, or lexical density $=100 \times$ number of content words/ total number of 
words (Schmitt, 2000; and Timarová, 2005, p. 68). Operationally, the researcher defines lexical density as the proportion of content words respect to the complete essay. This measure is calculated by dividing the lexical types or content words by the total words of the essay.

\section{- Lexical Variation}

Lexical variation, also known as lexical diversity (Malvern, Richards, Chipere, \& Dura'n, 2004a; Yu, 2007; and McCarthy \& Jarvis, 2013) refers to the range of a learner's vocabulary as displayed in his or her language use. Lexical variation is often used as an equivalent to lexical richness (Daller, Van Hout, \& Treffers-Daller, 2003, p. 200). However, Malvern et al. (2004b) begin their book about lexical variation with discussing the difference between lexical variation and lexical richness, stating that "lexical variation measure is only one part of the multidimensional feature of lexical richness" (p. 4). Johansson (2008, p. 75) identified lexical variation as a measure of how many different words that are used in a text (i.e. the more varied a vocabulary a text possesses, the higher lexical variation. For a text to be highly lexically diverse, the speaker or writer has to use many different words, with little repetition of the words already used). Lexical variation is defined as the ratio of the number of lexical types to lexical tokens. Other variants of lexical variation studied in Lu (2012, p. 41) included noun, adjective, modifier, adverb and verb variations, which represent the proportion of the words of the respective categories compared to all lexical words in the document. For the purpose of the study, Operationally, the researcher defines lexical variation as the ratio of the number of different lexical types (noun, adjective, adverb and verb variations) to all words in the essay.

\section{Morphological Awareness}

Morphological awareness, which is a vocabulary acquisition strategy, is the process of breaking down morphologically complex words into their constituent morphemes. McBrideChang et. al. (2005) defined morphological awareness as, "Awareness of and access to the meaning and structure of morphemes in relation to words". Morphological awareness refers to the students' knowledge of morphemes and morphemic structure which helps them to manipulate morphological 
structure of words (Carlisle and Stone, 2003). The conscious ability to think about and manipulate morphemes in words. (Carlisle, 1995, p. 249). Morphological awareness is an understanding that prefixes and suffixes can be added or taken away to change the meaning of a word (Echoke, \& Koda, 2017) . Morphological awareness refers to "the ability of a student to consciously consider the structure of words in terms of the smallest meaningful units and to analyze and manipulate these units" (Nagy, Abbott, Vaughan, Berninger, \& Vermeulen, 2003, p.731). The definition contains two critical components: (a) consciousness and (b) analysis. Operationally, morphological awareness is defined as the ability to consciously recognize, analyze and manipulate the structure of words in terms of morphemes (the smallest meaningful units of a language).

\section{Writing Performance}

Writing Performance is the production of text (Leki, 2007, p. 234) as a response to provided topics. To many wiring professionals, writing entails both the writing process and the results of the process. According to (Hyland, 2002: 6) writing ability is the capacity to produce "a contextually" correct forms of language, following prescribed patterns at either sentence or discourse level. Writing as a product is writing which serves to reinforce writing in foreign language in terms of grammatical and syntactic forms (Tangpermpoon, 2008, 2). However, the term FL writing performance was used in the current study to mean students' ability to build up grammatical, meaningful, cohesive and coherent text at appropriate level of lexical variation and density

\section{Significance of the Study}

This study may be significant for the following:

1- The results of the study might set an example showing the potential of using morphological awareness in developing lexical richness of EFL majors.

2- The study may contribute to highlighting the indirect reflection of morphological awareness training on writing performance.

3- The study calls for the inclusion of explicit instruction of morphological awareness in EFL teachers' educational 
programs as well as including how to teach and how to assess lexical richness as a part of the ELT methodology courses.

\section{Method}

\section{Participants}

The participants of this study were 60 first-year English major students chosen from the Faculty of Foreign Languages and Translation - Misr University for Science and Technology during the 2018 - 2019 academic year, whose age ranged from 19 to 21 . The students were divided into two equal groups of (30) students in the experimental group and (30) students in the control group.

\section{Instruments}

To fulfill the purpose of the current study, A pre-post writing test was developed by the researcher to measure the subjects' lexical richness of their written outputs in terms of two aspects, namely, lexical density and lexical variation (Appendix A). In the measurement of lexical density, the ratio of lexical / content words (i.e. nouns, verbs, adjectives, and adverbs) and the number of total words is calculated. For example, the sentence "the dog sat on the table" comprises 6 words and 3 content words, so the lexical density of this simple sentence $=\mathrm{NLex} / \mathrm{N}=$ $3 / 6=0.50$. Furthermore, to count lexical variation (LV), the Type/Token Ratio were applied. For the same example above, the number of types are 5 and the number of tokens are 6, so $L V=5 / 6=0.83$. The test total score was sixty.

\section{Procedure}

The treatment of the present study was carried out during the second semester of the academic year 2018-2019 in three main successive stages: pretesting, implementing the training program, and post-testing. After determining the level of the two groups in the dependent variable, participants of the experimental group were exposed to the training program for an hour per week and lasted for 11 hours with a total of 11 weeks during the second semester of the academic year 2018- 2019. The training program was designed to identify the meaning of "morpheme", classify morphemes into free and bound ones, practice the rules of word formation in English, illustrate derived 
and inflected morphemes, identifying types of affixes, generate new words using bound affixes, identify regular and irregular inflection, recognize inflections of nouns, verbs, adjectives and adverbs, and show interest to use more inflected words in writing.

The data was collected and tabulated through SPSS and analyzed using t-test to compare the means of pre-test and posttest of writing and to probe the effectiveness of morphological awareness training.

\section{Results and Discussion}

In order to test the research hypotheses, the Statistical Package (SPSS/PC+) was used to calculate the t-value for testing the difference between the mean scores of the experimental group and the control group on the pre-post writing test. In the following section, a discussion of the hypotheses is provided in order to investigate the final results of the treatment.

\section{The first hypothesis}

The results for the first research hypothesis of the study (There is a statistically significant difference between the mean scores of the experimental group learners and those of the control group in their lexical density as measured by the writing test after the treatment) are presented in Table (1).

Table (1): t-test results of the post-test comparing the experimental and the control groups in lexical density

\begin{tabular}{|l|c|c|c|c|c|c|c|}
\hline & Group & N & Mean & $\begin{array}{c}\text { Std. } \\
\text { Deviation }\end{array}$ & df & t & Sig. (2 tailed) \\
\hline \multirow{2}{*}{ Density } & Control & 30 & 32.94 & 5.07 & & 40.41 & 0.000 \\
\cline { 2 - 7 } & Experimental & 30 & 52.64 & 2.45 & 58 & & \\
\hline
\end{tabular}

Results in table (1) indicated that the control group students' mean score in lexical density of the post test was (32.94) whereas, the experimental group students' mean score was (52.64). These results indicate that the higher mean is in favour of the experimental group's post administration of the test. To sum up, the t-test of the paired sample results about the difference between the students' mean scores in lexical density 
of the post- administration of the test was statistically significant in favor of the experimental group indicating the effectiveness of morphological awareness training on lexical density. Therefore it can be said that morphological awareness training had a large effect on the experimental group students' lexical density on the post-test as compared to that of the control group students receiving regular instruction. So, the first hypothesis is accepted.

\section{The second hypothesis}

The results for the second research hypothesis of the study (There is a statistically significant difference between the mean scores of the experimental group learners in their lexical density as measured by the writing test before and after the treatment) are presented in Table (2).

Table (2): t-test results comparing the Mean of the pre- and post- test scores for the experimental group in lexical density

\begin{tabular}{|c|c|c|c|c|c|c|c|}
\hline Group & Test & $\mathbf{N}$ & Mean & $\begin{array}{c}\text { Std. } \\
\text { Deviation }\end{array}$ & df & $\mathbf{t}$ & Sig. (2 tailed) \\
\hline \multirow[b]{2}{*}{ Experimental } & pre & \multirow[b]{2}{*}{30} & 29.4 & 4.69 & \multirow[b]{2}{*}{29} & \multirow[b]{2}{*}{43.95} & \multirow[b]{2}{*}{0.000} \\
\hline & post & & 52.64 & 2.45 & & & \\
\hline
\end{tabular}

Results in table (2) indicate that the students' mean score in the lexical density of the pre-test was (29.4). On the other hand, their mean score in the lexical density of the post test was (52.64). These results indicate that the higher mean is for the post administration of the test. Therefore, students' lexical density have been improved after exposure to the proposed program.

The t-test of the paired sample results about the difference between the students' mean scores in lexical density of the preand post- administration of the test was statistically significant in favor of the post administration since the estimated $t$-value was (43.95). These results indicate that the morphological awareness training had a large effect on the experimental group students' lexical density on the post-test as compared to their lexical density on the pre-test, so the second hypothesis is accepted. 


\section{The third hypothesis}

The results for the third research hypothesis of the study (There is a statistically significant difference between the mean scores of the experimental group learners and those of the control group in their lexical variation as measured by the writing test after the treatment) are presented in Table (3).

Table (3): t-test results of the post-test comparing the experimental and the control groups in lexical variation

\begin{tabular}{|c|c|c|c|c|c|c|c|}
\hline & Group & $\mathrm{N}$ & Mean & $\begin{array}{c}\text { Std. } \\
\text { Deviation }\end{array}$ & df & t & Sig. (2 tailed) \\
\hline \multirow{2}{*}{ Variation } & Control & $\mathbf{3 0}$ & $\mathbf{2 6 . 3 4}$ & $\mathbf{3 . 2 3}$ & & \multirow{2}{*}{51.89} & \multirow{2}{*}{0.000} \\
\cline { 2 - 5 } & Experimental & $\mathbf{3 0}$ & $\mathbf{4 8 . 2 1}$ & $\mathbf{3 . 1 3}$ & $\mathbf{5 8}$ & \\
\hline
\end{tabular}

Results in table (3) indicated that the control group students' mean score in lexical variation of the post test was (26.34) whereas, the experimental group students' mean score was (48.21). These results indicate that the higher mean is in favour of the experimental group's post administration of the test. To sum up, the t-test of the paired sample results about the difference between the students' mean scores in lexical variation of the post- administration of the test was statistically significant in favor of the experimental group indicating the effectiveness of morphological awareness training on lexical variation. Therefore it can be said that morphological awareness training had a large effect on the experimental group students' lexical variation on the post-test as compared to that of the control group students receiving regular instruction. So, the third hypothesis is accepted.

\section{The fourth hypothesis}

The results for the fourth research hypothesis of the study (There is a statistically significant difference between the mean scores of the experimental group learners in their lexical variation as measured by the writing test before and after the treatment) are presented in Table (4).

Table (4): t-test results comparing the Mean of the pre- and post- test scores for the experimental group in lexical variation

\begin{tabular}{|c|c|c|c|c|c|c|c|}
\hline Group & Test & N & Mean & $\begin{array}{c}\text { Std. } \\
\text { Deviation }\end{array}$ & df & t & Sig. (2 tailed) \\
\hline \multirow{2}{*}{ Experimental } & pre & \multirow{2}{*}{3} & 21.31 & 5.49 & & & \multirow{2}{*}{ post } \\
\cline { 2 - 5 } & 30 & 48.21 & 3.13 & 29 & 36.15 & 0.000 \\
\hline
\end{tabular}


Results in table (4) indicate that the students' mean score in the lexical variation of the pre-test was (21.31). On the other hand, their mean score in the lexical variation of the post test was (48.21). These results indicate that the higher mean is for the post administration of the test. Therefore, students' lexical variation have been improved after exposure to the proposed program.

The t-test of the paired sample results about the difference between the students' mean scores in lexical variation of the preand post- administration of the test was statistically significant in favor of the post administration since the estimated t-value was (36.15). These results indicate that the morphological awareness training had a large effect on the experimental group students' lexical variation on the post-test as compared to their lexical variation on the pre-test, so the fourth hypothesis is accepted.

The results of the present study were consistent with the suggestion that students used morphological analysis in order to infer word meanings (Carlisle, 2007, and Sparks \& Deacon, 2015). Studies that have offered this interpretation suggested that students relied on morphemes and morphological awareness to aid their knowledge of morphologically complex words specifically. Results also showed that the morphological awareness activity can act as an initial step in word formation awareness and students may become more motivated to conduct their own word formation tasks in the upcoming English writings. Most of the students used suffixes correctly and more than what they were required in writing. According to various researches, prefixes make lexical recognition more difficult, especially if it is more difficult to identify the beginning of stems (Carlisle,2010; and Tahaineh, 2012). The results are consistent with those obtained by Vermeer (2000), Malvern, et al. (2004a), and $\mathrm{Yu}$ (2010), suggesting that explicit training of students on how to increase their word store did have an enhancing effect on learners' lexical richness.

Moreover, results revealed that morphological awareness also made a direct, unique contribution to lexical richness. This finding converged with prior findings from studies conducted with smaller samples of monolingual English speakers (Ku \& Anderson, 2003; and Nagy et al., 2003). The benefits gain from 
the study strategy, which is in agreement with Apel \& Diehm (2014) who stated that the benefits from morphological awareness activities, may be due to the gradual steps that the teacher adopted in sequencing the activities of the course. This helped enhance students' autonomy and provided them a sense of fulfillment, which encouraged them to participate and gain useful skills. Also, it seems that morphological awareness strategy bridges the gap between theory and practice of morphological knowledge.

The results of the present study are consistent with those revealed by Bellomo, (2009); Jeon, (2011); Law, Wouters \& Ghesquiere (2015); and Echoke \& Koda,( 2017) who all indicated a positive effect of morphological awareness on developing college and adult students English language skills. As the findings of this study suggested, the learners' morphological awareness had significant effect on their lexical richness. This finding is in agreement with other studies (Chang et al., 2005; and Nurhemida, 2007) that were indicative of a close connection between language learners' morphological awareness and their level of success in particular aspects of vocabulary learning. Moreover, it also supported Carlisle's (2000) and $\mathrm{Ku}$ and Anderson's (2003) claimed that morphological knowledge was closely correlated with comprehension. The results of the present study were also consistent with the suggestion that pupils used morphological analysis in order to infer word meanings (e.g., Carlisle, 2007; and Sparks \& Deacon, 2015). Studies that have offered this interpretation suggested that pupils relied on morphemes and morphological awareness to aid their knowledge of morphologically complex words specifically. This study suggested that morphological awareness played a role in the development of lexical density and lexical variation.

The results of this study also suggested that the facilitative effects of morphological awareness on lexical richness as improved awareness of derivational and inflectional morphology might yield some increases in the speed with which students recognized words. These results also implied that the effect of morphological awareness on lexical richness should be achieved through learners' lexical inferencing skill. As a result, those learners who possessed better morphological awareness tended 
to learn words better, and in turn, held a larger word store. The results also revealed that morphological awareness, in addition contributing to lexical richness via lexical inferencing ability. Existence of this effect wasn't surprising, because learners' insights into stems, affixes, and word structure, while helping with meaning inference, also strengthen their representation of words in the mental lexicon. These results also show that learners make more repetitions of most frequently used words i.e. nouns and verbs before the treatment. There is a tendency for learners to make use of the vocabulary after the treatment. These differences are consistent with the concept of language proficiency that assumes that richer lexical density and high lexical variety are characteristic of better language knowledge .

\section{Conclusion}

It can be concluded that morphological awareness is a critical factor in enabling students to clear understand prefixes, suffixes and word formation. Students tried to create new words using the prefixes and suffixes which shows their excitement towards learning of word formation. Students use words repeatedly because they have limited vocabulary. It can be concluded that word formation activity was interesting for students and they wanted to learn through it. These kinds of activities should be a part of English courses and according to the students' want, such kind of activities should be conducted weekly or biweekly. Several researches managed to get the similar outcomes that students who get familiar with the formation and meaningful construction of prefixes and suffixes show better performance in English language exercises (Kieffer \& Box, 2013). The lexical richness can be measured by lexical density, and lexical variation. Each of the two types underlying lexical richness can be used in measuring the effect of lexicon on EFL majors' writing. In writing, students can explore their thoughts or ideas to express their feeling with their own words. This study has shown that both the lexical density and lexical variety can play an effective role in the language performance. Though the lexical density contributes to the proficiency of the learners and lexical variety affects the performance of the learners as a whole. The students can be identified in terms of lexical variety and density. The study also presents that it can be 
expected students' lexical development as measured by lexical density and lexical variety to be reflected in the learner's productive use of proficiency in the use of lexicon and language performance.

As such, the study concluded that training on morphological awareness had greater effects on developing lexical richness, such as identifying the written form of the word, recognizing the entire parts of the word, recognizing the part of speech of the word, recalling the appropriate meaning for a word form, recognizing correct uses of the word in context, relating the word to its synonyms or antonyms, categorizing the meaning set of different words, recalling appropriate collocations, identifying the grammatical mistake of a given word, producing appropriate inflected and derived forms of the word, writing an appropriate word form to express a specific meaning, writing an appropriate word meaning to express a specific word form, writing a word that belongs to a certain meaning set, producing common synonyms or antonyms for a word, using a word in the correct grammatical pattern and producing the word with appropriate collocations.

\section{Recommendations}

Based on the conclusions drawn from the results reached, the following recommendations seem pertinent:

1- Proper instruction of word formation activities should be included in the English language courses.

2- It is highly necessary for EFL teachers to be trained on how to teach morphological awareness to help their students advance their lexical richness.

3- Teachers should give individual attention to students to form new words.

4- Students should benefit from the rules of how English words are formed. Students should be taught morphological rules so that they perform better in writing.

5- Intensive training of morphological awareness might help students develop all language skills due to their acquired ability from morphological analysis to infer the words' meaning and form.

6- Examining lexical richness in the current study is limited to only two aspects, lexical density and variation. It is recommended to research lexical sophistication and lexical errors to have a larger view of the learners' lexical richness. 


\section{References}

- Apel, K., \& Diehm, E. (2014). Morphological awareness intervention with kindergarteners and first and second grade students from low SES homes: A small efficacy study. Journal of Learning Disabilities, 47, 65-75.

- Apel, K., Diehm, E., \& Apel, L. (2013). Using multiple measures of morphological awareness to assess its relation to reading. Topics in Language Disorders,33 (1), 42 - 56.

- Bellomo, T (2009). Morphological analysis and vocabulary development: critical criteria. The Reading Matrix, 9(1), 44-55.

- Biber, D. (1999). Longman grammar of spoken and written English: New York: Longman.

- Birch, B. (2007). English L2 reading: Getting to the bottom (2nd ed.). Mahwah, NJ: Lawrence Erlbaum.

- Bowers, P., Kirby, J., \& Deacon, S. (2010). The effects of morphological instruction on literacy skills: A systematic review of the literature. Review of Educational Research, 80(2), 144-179.

- Carlisle, J. (1995). Morphological awareness and early reading achievement. In L. B. Feldman (Ed), Morphological aspects of language processing (pp. 189-209). Hillsdale, NJ: Erlbaum.

- Carlisle, J. (2000). Awareness of the structure and meaning of morphologically complex words: Impact on reading. Reading and Writing, 12(3), 169-190.

- Carlisle, J. (2007). Fostering morphological processing, vocabulary development, and reading comprehension. Vocabulary acquisition: Implications for reading comprehension , 78-103.

- Carlisle, J. (2010). Effects of instruction in morphological awareness on literacy achievement: An integrative review. Reading Research Quarterly, 45(4), 464-487.

- Carlisle, J., \& Fleming, J. (2003). Lexical processing of morphologically complex words in the elementary years. Scientific Studies of Reading, 7(3), 239-253.

- Carlisle, J. \& Stone, C. (2003). The effect of morphological structure on children's reading derived words in English. In E. M. Assink, \& D. Sandra. (Eds). (2003). Reading complex words: cross- language studies (27- 52). New York: Kluwer Academic/ Plenum Publishers.

- Caselli, N., Caselli, M., \& Goldberg, A. (2016). Inflected words in production: Evidence for a morphologically rich lexicon. Quarterly Journal of Experimental Psychology, 69(3), 432-454.

- Chang, C., Wagner, R., Muse, A., \& Chow, H. (2005).The role of morphological awareness in children's vocabulary acquisition in English. Applied Psycholinguistics, 26, 415-435. 
- Daller, H., van Hout, R. \& Treffers-Daller, J. (2003). Lexical richness in the spontaneous speech of bilinguals. Applied Linguistics, 24 (2). 197-222.

- Daller, J. (2010). Operationalizing and measuring language dominance. International Journal of Bilingualism, 15(2),147-163.

- Djiwandono, P. (2016). Lexical Richness In Academic Papers: A Comparison Between Students' And Lecturers' Essays. Journal of Applied Linguistics, 5(2).

- Echoke, S. \& Koda, K. (2017). Contribution of morphological awareness to adult L2 Chinese word meaning inferencing. The Modern Language Journal, 101(4), 742-755.

- Fracasso, L., Bangs, K., \& Binder, K. (2014). The contributions of phonological and morphological awareness to literacy skills in the Adult Basic Education population. Journal of Learning Disabilities.

- Gharibi, K., \& Boers, F. (2017). Influential factors in lexical richness of young heritage speakers' family language: Iranians in New Zealand. International Journal of Bilingualism.

- Green, L., McCutchen, D., Schwiebert, C., Quinlan, T., EvaWood, A., \& Juelis, J. (2003). Morphological development in children's writing. Journal of Educational Psychology, 95(4), 752-761.

- Halliday, M. (1989). Spoken and written language. Oxford: Oxford University Press.

- Hyland, K. (2002). Teaching and researching writing. London: Longman.

- Herman, J., Gilbert Cote, N., Reilly, L., \& Binder, K. ( 2013 ). Literacy skill differences between adult native English and native Spanish speakers. Journal of Research and Practice for Adult Literacy, Secondary, and Basic Education,2(3), 147 - 155.

- Hoover, D. (2003). Another perspective on vocabulary richness. Computers and Humanities, 37, 151-178.

- Jacobs, H., Zingraf, S., Wormuth, D., Hartfield, V., \& Hughey, J. (1981). Testing ESL compositions: a practical approach. Rowley, Mass: Newbury House.

- Jeon, E. (2011). Contribution of morphological awareness to second language reading comprehension. The Modern Language Journal,. 95(2), 217-235.

- Johansson, V. (2008). Lexical diversity and lexical density in speech and writing: a developmental perspective. Lund University, Dept. of Linguistics and Phonetics. Working Papers, 53, 61-79.

- Kieffer, M. \& Box, C. (2013). Derivational morphological awareness, academic vocabulary, and reading comprehension in Spanish-speaking language minority learners and their classmates. Learning and Individual Differences, 24, 168-175. 
- Ku, Y. \& Anderson, R. (2003). Development of morphological awareness in Chinese and English. Reading and Writing, 16(5), 399-422.

- Kuo, L. \& Anderson, R. (2006). Morphological awareness and learning to read: A cross-language perspective. Educational Psychologist, 41, 161-180.

- Kyle, K., \& Crossley, S. (2016). The relationship between lexical sophistication and independent and source-based writing. Journal of Second Language Writing, 34, 12-24.

- Laufer, B. \& Nation, P. (1995). Vocabulary size and use: lexical richness in L2 written production. Applied Linguistics, 16(3), $307-322$.

- Law, J., Wouters, J. \& Ghesquiere, P. (2015). Morphological awareness and its role in compensation in adults with dyslexia. Dyslexia, 21(3), 254-272.

- Leki, I (2007). Undergraduates in a second language: Challenges and complexities of academic literacy development. New York, NY: Lauren Earlbaum Associates.

- Liu, P., \& McBride-Chang, C. (2010). What is morphological awareness? Tapping lexical compounding awareness in Chinese third graders. Journal of Educational Psychology, 102(1), 62-73.

- Lu, X. (2012). The relationship of lexical richness to the quality of ESL learners' oral narratives. The Modern Language Journal, 96(2), 190-208.

- Maag, L. (2007). Measuring morphological awareness in adult readers: Implications for vocabulary development (Unpublished doctoral dissertation). University of Florida, Gainesville.

- Malvern, D. \& Richards, B. (2012). Measures of lexical richness. In The Encyclopedia of Applied Linguistics.

- Malvern, D., Richards, B., Chipere, N., \& Durán, P. (2004a). Developmental trends in lexical diversity. Applied Linguistics, 25(2), 220-242.

- Malvern, D., Richards, B., Chipere, N., \& Durán, P. (2004b). Lexical diversity and language development: Quantification and assessment. Houndmills, England: Palgrave MacMillan.

- McBride-Chang e, C., Wagner, R., Muse, A., Chow, B., \& Shu, H. (2005). The role of morphological awareness in children's vocabulary acquisition in English. Applied Psycholinguistics, 26, 415-235.

- McCarthy, P., \& Jarvis, S. (2013). From intrinsic to extrinsic issues of lexical diversity assessment. In S. Jarvis \& M. Daller (Eds.), Vocabulary knowledge: Human ratings and automated measures (pp. 45-78). Amsterdam: John Benjamins. 
- McCutchen , D., Green, L. , \& Abbott, R. ( 2008 ). Children's morphological knowledge: Links to literacy. Reading Psychology,29 (4), $289-314$.

- Mitchell, R. \& Myles, F. (2004). Second language learning theories. London: Hodder Arnold.

- Morin, R. (2003). Derivational morphological analysis as a strategy for vocabulary acquisition in Spanish. The Modern Language Journal, 87, 200-221.

- Nagy, W., Berninger, V., Abbott, R., Vaughan, K., \& Vermeulen, K. (2003). Relationship of morphology and other language skills to literacy skills in at-risk second-grade readers and at risk fourth grade writers. Journal of Educational Psychology, 95, 730-742.

- Nagy, W., Carlisle, J., \& Goodwin, A. (2014). Morphological knowledge and literacy acquisition. Journal of Learning Disabilities, 47(1), 3-12.

- Nurhemida, (2007). The relationship between morphological awareness and English vocabulary knowledge of Indonesian senior high school students. Unpublished master's thesis, University of Queensland, St Lucia, Australia.

- Oz, H. (2014). Morphological awareness and some implications for English language teaching. Procedia-Social and Behavioral Sciences, 136, 98-103.

- Perfetti, C. (2007). Reading ability: Lexical quality to comprehension. Scientific Studies of Reading, 11(4), 357-383.

- Read, J. (2000). Assessing vocabulary. Cambridge University Press.

- Schiff, R., \& Calif, S. (2007). Role of phonological and morphological awareness in L2 oral word reading. Language Learning, 57(2), 271-298.

- Schmitt, N. (2000). Vocabulary in language teaching. New York: Cambridge University Press.

- Siskova, Z (2012). Lexical richness in EFL students' narratives. Language Studies Working Papers, University of Reading, 4, 26 $-36$.

- Sparks, E., \& Deacon, S. (2015). Morphological awareness and vocabulary acquisition: A longitudinal examination of their relationship in English-speaking children. Applied psycholinguistics, 36(2), 299-321.

- Suggate, S., \& Stoeger, H. (2017). Fine Motor Skills Enhance Lexical Processing of Embodied Vocabulary: A Test of the Nimble-Hands, Nimble-Minds Hypothesis. Quarterly Journal of Experimental Psychology, 70(1), 2169-2187. 
- Tahaineh, Y. (2012). The Awareness of the English Wordformation Mechanisms is a Necessity to Make an Autonomous L2 Learner in EFL Context. Journal of Language Teaching \& Research, 3(6).

- Tangpermpoon, T. (2008). Integrated approaches to improve students writing skills for English major students. $A B A C$ journal, 28(2)

- Tighe, E., \& Binder, K. ( 2013 ). An investigation of morphological awareness and processing in adults with low literacy. Applied Psycholinguistics.

- Tighe, E., \& Binder, K. (2014). Investigating morphological awareness and the processing of transparent and opaque words in adults with low literacy skills and in skilled readers. Journal of Research in Reading.

- Timarová, Š. (2005): Corpus linguistics methods in interpreting research: a case study. The Interpreters' Newsletter, 13, 65-70.

- Venezky, R. (1999). The American way of spelling. New York: Guilford Press.

- Vermeer, A. (2000). Coming to grips with lexical richness in spontaneous speech data. Language Testing, 17, 65-83.

- Viadkovic, I. \& Barker, F. (2009). Lexical development across second language proficiency levels: a corpus informed study. From http://www.baal.org.uk/proc09 /vidakovic barker.pdf

- Yu, G. (2007). Lexical diversity in MELAB writing and speaking task performances. Span Fellow Working Papers in Second or Foreign Language Assessment, 5, 2007. English Language Institute, University of Michigan.

- Yu, G. (2010). Lexical diversity in writing and speaking task performances. Applied Linguistics, 31, 236-259.

- Zhang, Y. (2014). A corpus based analysis of lexical richness of Beijing Mandarin speakers: variable identification and model construction. Language Sciences, 44, 60-69. 